\title{
The role of freshwater fluxes in the thermohaline circulation: Insights from a laboratory analogue
}

\author{
Julia C. Mullarney ${ }^{\mathrm{a}, *}$, Ross W. Griffiths ${ }^{\mathrm{b}}$, Graham O. Hughes ${ }^{\mathrm{b}}$ \\ ${ }^{a}$ Department of Oceanography, Dalhousie University, Halifax, N.S., Canada B3H $4 \mathrm{~J} 1$ \\ ${ }^{\mathrm{b}}$ Research School of Earth Sciences, The Australian National University, Canberra, ACT 0200, Australia
}

Received 27 January 2006; received in revised form 13 September 2006; accepted 3 October 2006

\begin{abstract}
Regime transitions in the meridional overturning circulation (MOC) and the rate of formation of deep and bottom waters are thought to be sensitive to changes in the freshwater flux at high latitudes. We model convective overturning in the presence of a surface freshwater input using laboratory experiments that are inverted relative to the ocean: we establish an equilibrium circulation forced by differential heating and cooling along the base of a box and perturb this flow by adding a stabilizing saltwater input at the 'polar' end of the box. An initially stable layer forms near the source of the salinity anomaly as a 'polar halocline'. The subsequent circulation is governed largely by the ratio of salinity and thermal buoyancy supply. For small values of this ratio we observe periodic formation and breakdown of the halocline. Larger values of the flux ratio lead to subthermocline intrusions and stable layering laterally throughout the basin, isolating the bulk of the water column from the forcing boundary. The shutdown of deep overturning and formation of a shallow circulation occurs at a salinity buoyancy input of order 0.1 times the rate of loss of thermal buoyancy. This salinity buoyancy is then comparable to the buoyancy that forces the deep sinking plume below the thermocline in steady-state overturning. When the salinity buoyancy flux is removed, the circulation slowly returns to its original state.
\end{abstract}

(C) 2006 Elsevier Ltd. All rights reserved.

Keywords: Thermohaline circulation; Meridional overturning; Freshwater flux; Halocline catastrophe; Oscillations; Horizontal convection

\section{Introduction}

Differential heat fluxes at the ocean's surface lead to a latitudinal upper ocean temperature gradient balanced by poleward flow and heat transport. At high latitudes the surface waters cool, mix with

\footnotetext{
*Corresponding author. Tel.: + 19024942203 ; fax: +19024942885 .

E-mail addresses: julia.mullarney@dal.ca (J.C. Mullarney), ross.griffiths@anu.edu.au (R.W. Griffiths), graham.hughes@anu.edu.au (G.O. Hughes).
}

more saline waters (formed by brine rejection from the freezing sea ice) and sink to form 'deep' and 'bottom' waters. There is also an influx of freshwater at high latitudes owing to an annual-average excess of evaporation over precipitation in the tropics and net precipitation in the high latitudes, which appears in the oceans in part as river and ice sheet runoff (Broecker et al., 1990; Rahmstorf, 1996). The freshwater reduces the density of the surface waters and this effect tends to oppose overturning flow caused by the temperature gradient and the seasonal rejection of brine during sea ice 
production. During climate fluctuations involving warming at high latitudes, a net melting of ice sheets leads to an increased freshwater input at the ocean surface (Broecker, 1994).

Stommel (1961) hypothesized that the thermohaline circulation may have more than one mode of circulation and illustrated this using a simple box model in which surface and abyssal flows are exchanged through pipes between high- and lowlatitude reservoirs of different temperatures and salinities. The system exhibits a bifurcation and hysteresis, with stable solutions on different solution branches corresponding to either a 'thermally driven' flow, in which the temperature differences dominate the density differences (as described above), or a 'salinity-driven' flow, in which the salinity variations dominate the density. In the oceans, the 'salinity-driven' solution corresponds to a situation in which freshwater input into the highlatitude oceans prevents cold water from sinking there to large depths from the surface. Evaporation at low latitudes dominates instead, leading to the sinking of warm salty water in the equatorial oceans. Corresponding flow regimes are found in a variety of box models (Rooth, 1982; Walin, 1985), and numerical ocean simulations (Marotzke and Willebrand, 1991; Stocker and Wright, 1991; Rahmstorf, 1995). Multiple equilibrium states, hysteresis and abrupt transitions between stable flow states have been confirmed in laboratory analogue box models (Whitehead, 1996; Whitehead et al., 2003; Whitehead and Bradley, 2006). However, in contrast to the oceans where the buoyancy is added and removed only at the ocean surface, these models did not confine forcing to a horizontal boundary.

Fluctuations in the thermohaline circulation are thought to be caused by modest changes in the highlatitude freshwater input to the oceans (Marotzke and Willebrand, 1991; Stocker and Wright, 1991; Manabe and Stouffer, 1995; Rahmstorf, 1995; and see reviews by Broecker et al., 1985; Stocker, 2000). It has been argued that the present day North Atlantic circulation may not be far from the instability threshold beyond which deep water formation cannot be sustained (Tziperman et al., 1994; Rahmstorf, 1996; Tziperman, 2000). The existence of intermediate states between the 'on' and 'off' states for North Atlantic deep water formation has also been hypothesized. A coupled ocean-atmosphere-ice model (Tziperman, 1997) exhibits large-amplitude oscillations in the strength of the overturning circulation and both two- and three-dimensional ocean GCMs (Winton and Sarachik, 1993) show self-sustained oscillations and 'halocline catastrophes' at regular intervals. Such oscillations have been predicted to occur on millennial (Weijer and Dijkstra, 2003; Colin De Verdiére et al., 2006) as well as on decadal and interdecadal timescales (Weaver et al., 1991; Huck et al., 1999; Te Raa and Dijkstra, 2002). Whitehead et al. (2005) find similar oscillations to those reported here with the growth and overturning of a freshwater layer in a laboratory box model of a thermohaline system. Numerical solutions to their analytical model revealed the oscillation period varied inversely with the strength of the temperature forcing.

A conceptual model for the zonally integrated overturning component of the ocean circulation is the convective flow produced by a meridional surface temperature gradient (Stommel, 1962). These 'horizontal convection' flows forced by heating and cooling at one horizontal boundary were first examined in the laboratory by Rossby (1965), who imposed a linear temperature gradient along the base of a box of aspect ratio $H / L=0.4$, where $H$ is the height and $L$ is the length. The Rayleigh numbers (based on the box length) ranged up to $10^{10}$ and the flow remained laminar throughout. Related numerical solutions (Rossby, 1998) were found in a box of aspect ratio 1, with Rayleigh numbers ranging up to $10^{8}$. As predicted by Stommel (1962), the resulting circulation was highly asymmetric. Upwelling through the full depth of the box was confined to a narrow and relatively fast plume against the endwall above the hot end of the box.

Mullarney et al. (2004) (hereafter MGH04) extended the problem considered by Rossby (1965, 1998) using experiments in a long shallow tank with larger Rayleigh numbers (of $\mathrm{O}\left(10^{2}\right)$ greater than Rossby's experiments and of $\mathrm{O}\left(10^{4}\right)$ greater than Rossby's numerical solutions). Piecewise-uniform thermal forcing consisted of a constant heat flux applied to one half of the base, while the other half of the base was held at a fixed temperature, which cooled the water in direct contact with the base and maintained a stable thermal boundary layer above. Two novel features observed in these experiments were that the vertical plume on the endwall was turbulent, and that a boundary-layer instability formed a convective mixed layer (CML) above the heated half of the base. Mixing eroded the stable 
thermal boundary layer such that the mixed layer deepened with distance from the midpoint of the box until, at the end of the box, it penetrated through the strong density stratification and fed directly into the rising plume. The plume outflow along the opposite horizontal boundary, too, contained large eddying structures. The flow and density distribution have been predicted using a turbulent plume and modified diffusive 'filling box' theory applied to the oceans (Hughes and Griffiths, 2006) and to the relatively simple laboratory box (Hughes et al., 2006).

In the present study we modify the thermal convection experiments of MGH04 to mimic an imposed freshwater buoyancy input at the polar end of the box, and examine the complex interaction between opposing stabilizing and destabilizing buoyancy inputs. We concentrate on the case of thermal forcing in a single hemisphere and a step change with time in the freshwater input. We find multiple regimes, including oscillatory flow and shutdown of the deep overturning.

\section{Governing parameters}

We now consider the addition of a finite volume flux source of salinity anomaly (Fig. 1) to the purely thermally forced flow considered by MGH04. The flow is assumed to be Boussinesq and the important parameters in our experiments are the specific buoyancy fluxes of heat $B_{T}=g \alpha q / \rho_{0} c_{p}$ and salinity $B_{S}=g \beta \Delta S Q$, the volume flux $Q$ of salt solution, the box length $L$, height $D$ and width $W$, the molecular diffusivities of heat $\kappa_{T}$ and salt $\kappa_{S}$ and the viscosity $v$ of the working fluid. Here, $g$ is the gravitational acceleration, $\alpha$ and $\beta$ are the expansion coefficients

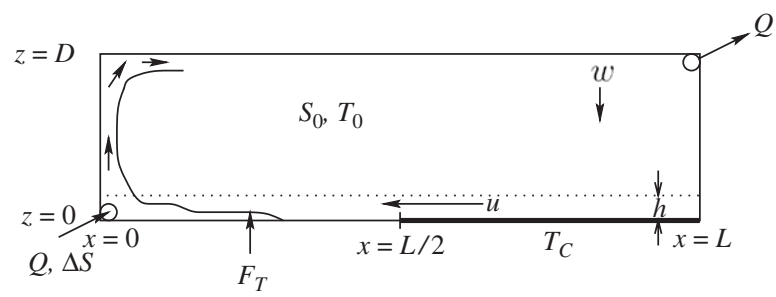

Fig. 1. Definition of the idealized problem. The $T_{0}$ and $S_{0}$ denote the temperature and salinity in the interior of the box in equilibrium. There is a thermal boundary layer (dashed line) of thickness $h$ and horizontal velocity $u$ along the base. A convectively mixed layer forms above the heated half of the base and there is a plume rising to the top of the box at the left-hand endwall (solid line). There is a slow downwelling velocity $w$ in the interior. The height of the box is exaggerated relative to its length. for heat and salt, respectively, $q=F_{T} W L / 2$ is the rate of heat input, $F_{T}$ is the heat flux (per unit area), $\rho_{0}$ and $c_{p}$ are the reference density and specific heat capacity, respectively, of the working fluid and $\Delta S$ is the salinity anomaly of the salt solution.

Dimensional considerations suggest that these parameters may be reduced to seven dimensionless groups, which may be summarized as the flux Rayleigh number, the ratio of buoyancy fluxes and a Péclet number,

$R a_{F}=\frac{g \alpha F_{T} L^{4}}{\rho_{0} c_{p} v \kappa_{T}^{2}}, \quad \frac{B_{S}}{B_{T}}=\frac{2 \beta \Delta S Q \rho_{0} c_{p}}{\alpha F_{T} W L}$

and

$P e=\frac{Q}{W \kappa_{T}}$,

respectively, and the Prandtl number, diffusivity ratio, aspect ratio and lateral aspect ratio,

$\operatorname{Pr}=\frac{v}{\kappa_{T}}, \quad \tau=\frac{\kappa_{S}}{\kappa_{T}}, \quad A=\frac{D}{L}$

and

$A_{W}=\frac{W}{L}$,

respectively.

In the experiments water was used as the working fluid. We selected the total heat input and thereby the thermal specific buoyancy $B_{T}$ and the Rayleigh number $R a_{F}$. We varied the source salinity anomaly $\Delta S$ and volume flux $Q$ in order to vary $B_{S}$. Thus, varying $\Delta S$ changed the buoyancy flux ratio $B_{S} / B_{T}$, whereas varying the volume flux $Q$ changed both $B_{S} / B_{T}$ and $P e$. However, variations in $P e$ will not be dynamically significant if the volume flux is much smaller than the boundary-layer volume flux $W L w \sim W u h \sim W \kappa_{T} R a_{F}^{1 / 6}$ associated with the thermal convection (MGH04), where $w$ is the downwelling velocity into the boundary layer, $u$ is the boundarylayer velocity and $h$ is the boundary-layer thickness. This requires that the ratio of these two volume fluxes $Q / W L w \sim P e R a_{F}^{-1 / 6} \ll 1$ ( or $P e \ll R a_{F}^{1 / 6}$ ), which is true for the range of conditions considered here. Molecular properties were approximately constant, and were evaluated at the average interior temperature $\left(24-45^{\circ} \mathrm{C}\right.$, depending on $\left.F_{T}\right)$, giving $\tau \approx 0.01$ and $3.98 \leqslant P r \leqslant 6.18$. We assume the flow is twodimensional and therefore neglect variations of the lateral aspect ratio $A_{W}=0.16$. 


\section{The experiments}

\subsection{Apparatus}

The laboratory apparatus is illustrated in Fig. 2 and is the same as that used by MGH04 for thermally forced overturning. The experiments were carried out in two tanks: early experiments used a preexisting apparatus and later experiments used a purpose-built apparatus (Fig. 2), which was designed to reduce sidewall heat loss and to improve the accuracy of the uniform fixed temperature boundary condition on the cooled half of the base. The results from the first tank are included here as they are consistent with and supplement those from the second apparatus. The thermal forcing conditions are the same as those in MGH04, but we also introduce a salinity buoyancy flux. Thus, convection in the long rectangular tanks is forced by uniform temperature over one half of the base and uniform imposed heat flux over the other half. The experiment is inverted (relative to the oceans) for convenience in setting up and operating the apparatus. The fixed flux boundary condition is used to facilitate more accurate knowledge of both the flux and temperature difference. With constant forcing the flow must evolve to a thermal equilibrium in which the heat removed through the cooled plate matches the imposed heat input to the other half of the base (less any heat losses to the room).

The inner dimensions of the first tank were length $L=1.2 \mathrm{~m}$, width $W=0.15 \mathrm{~m}$ and depth $D=0.2 \mathrm{~m}$. The walls were made of $6 \mathrm{~mm}$ thick glass, and a $6 \mathrm{~mm}$ thick sheet of aluminium formed the base. A $73 \mathrm{~mm}$ thick block of expanded polystyrene foam formed the lid of the tank and was placed in direct contact with the surface of the water. Foam was also used to insulate the walls of the tank: the endwall insulation was $100 \mathrm{~mm}$ thick and the sidewall insulation used $50 \mathrm{~mm}$ thick foam sheets, which could be easily removed to allow visualization of the flow. A $600 \mathrm{~mm} \times 150 \mathrm{~mm}$ electric heating mat was clamped under the left-hand half of the aluminium base above a $47 \mathrm{~mm}$ sheet of polystyrene foam. The heating mat provided a total rate of heating $\left(F_{T} W L / 2\right)$ between 68 and $258 \mathrm{~W}$, uniformly distributed over its area (i.e. $756 \leqslant F_{T} \leqslant$ $2867 \mathrm{~W} \mathrm{~m}^{-2}$ ). A heat exchanger was clamped directly under the other half of the base. This heat exchanger consisted of an aluminium block containing a network of water channels (with a copper capping plate), through which cooled water was pumped from a reservoir held at a temperature that was constant to within $\pm 0.02^{\circ} \mathrm{C}$. For further basal insulation the entire apparatus was placed on a $50 \mathrm{~mm}$ slab of close packed foam above a $100 \mathrm{~mm}$ thick expanded polystyrene sheet, and the sidewall

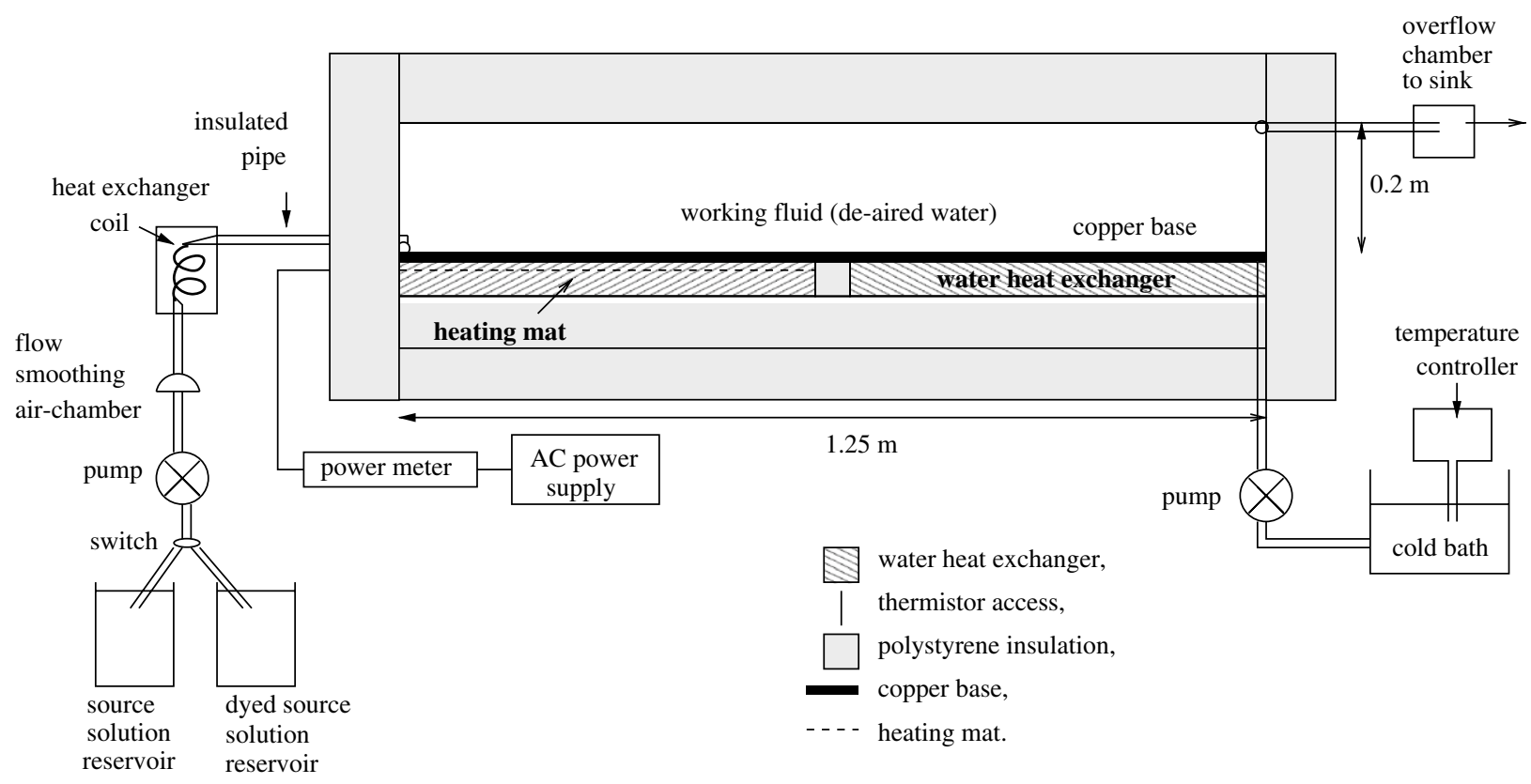

Fig. 2. The experimental apparatus. 
insulation covered the edges of heating and cooling sources.

The second tank was acrylic, with width and depth the same as those of the original tank. The length was increased slightly to $1.25 \mathrm{~m}$. The sidewalls were double-glazed with interior and exterior walls 20 and $3 \mathrm{~mm}$ thick, respectively. The $20 \mathrm{~mm}$ cavity between the walls was filled with argon. The outer sidewall extended downwards to enclose the base, heating mat and heat exchanger. The endwalls were $20 \mathrm{~mm}$ thick. A lid for the tank was constructed out of $10 \mathrm{~mm}$ thick acrylic with vertical tubes allowing thermistor access. The tank was also tightly insulated with polystyrene foam of thicknesses $150 \mathrm{~mm}$ below the base, $96 \mathrm{~mm}$ on the endwalls, $100 \mathrm{~mm}$ on the lid and removable sheets of $50 \mathrm{~mm}$ thickness on the sidewalls. The base of the tank was a single $10 \mathrm{~mm}$ thick copper plate. The same heating mat as used in the previous tank was clamped under the heated side of the base. A specially fabricated heat exchanger was placed under the right-hand side of the base. This heat exchanger was designed to bring the coolant water, circulating through channels in a block of ultra high-density polyethylene ('Tivar'), into direct contact with the overlying copper base. Compared with the previous apparatus, this heat exchanger reduced the temperature difference between the coolant and the top surface of the base, greatly improved the uniformity of the boundary temperature and reduced heat loss through the base of the heat exchanger. The areas over which the thermal forcing was applied were again $600 \times 150 \mathrm{~mm}$, but an additional $50 \mathrm{~mm}$ 'spacer' was added between the heating mat and cooling heat exchanger to reduce 'short-circuiting' of heat flow by horizontal conduction in the copper base.

For each tank, the effectiveness of the insulation was evaluated by monitoring the rate of cooling of water in the tank with no base heating or cooling. A heat transfer coefficient was found and later used to estimate the loss as a function of the temperature difference between the tank and the room. The losses were typically $3 \%$ of the applied basal heat supply. The Rayleigh number and thermal buoyancy flux were then based on the heat flux extracted through the cooled base (calculated from the known power provided to the heating mat less the estimated losses).

The stabilizing salinity buoyancy flux was introduced into the tank through a line source, consisting of a narrow slit along a horizontal tube, placed across the base at the left-hand (heated) end of the tank. The salt solution of concentration $S_{0}+\Delta S$, leading to a density anomaly $\Delta \rho / \rho_{0}=\beta \Delta S$ $(\sim 0.15-3.5 \%)$, was delivered from a source reservoir at a constant volume flux $Q$ by a peristaltic pump with a flow-smoothing surge chamber in the outlet. A second source reservoir was filled with dyed salt solution (of the same density) and could be switched in when required. In order to ensure that the source buoyancy flux did not have a thermal component, the salt solution was passed through a heat exchanger coil to raise it to the same temperature as the hot boundary layer at the injection point. The source fluid entered with little momentum and at a rate that was uniform across the width of the box.

The volume of water in the tank was held constant by placing a line sink (identical to the source) in the top right-hand corner of the tank. This sink allowed fluid to leave the tank through an overflow at a rate equal to that supplied by the source. Any dynamical effects of the sink were negligible, as temperature and salinity differences throughout most of the length and depth of the box were extremely small, as was the sink volume flux.

\subsection{Procedure}

A total of 60 experiments were carried out (30 in each tank) using a range of heat fluxes, source salinities and source volume fluxes. The tank was filled with deaired water, the heating mat and cooling pumps were switched on and the system was left to reach a thermally equilibrated state. The equilibration process took at least $24 \mathrm{~h}$ (but can be greater than $40 \mathrm{~h}$, depending on the imposed heat input and the water temperature when both heating and cooling are turned on) and was continuously monitored by thermistors in the tank. The strength of the circulation and temperature differences were set by the imposed heat flux, whereas the absolute temperature of the working fluid was controlled by the temperature of the cold plate. For experiments with a given imposed heat flux, and a temperature of approximately $16^{\circ} \mathrm{C}$ in the cold plate (measured by a thermistor within the copper base $100 \mathrm{~mm}$ from the endwall), the internal temperatures in the second tank were approximately $5{ }^{\circ} \mathrm{C}$ larger than in the first tank. This difference was a result of a more uniform cold plate temperature and reduced sidewall heat losses in the second tank. Rayleigh numbers varied in the range $6.05 \times 10^{13} \leqslant R a_{F} \leqslant 4.65 \times 10^{14}$ and 
were evaluated using fluid properties at the mean interior temperature. In the equilibrium state of the thermally forced flow, there was always a turbulent plume extending to the top of the tank against the endwall above the heated base, so that the whole volume of the tank took part in the overturning circulation.

After thermal equilibrium had been reached, the peristaltic pump was switched on to introduce the salt solution at a constant rate. The pump flow rate setting was measured in each experiment prior to commencing the input of salt water. We note that because the sink removed tank water of lower salinity than the source water, the mass of salt injected exceeded that withdrawn. Hence the experiment was unsteady. However, the pumping rate $Q$ $\left(=0.09-1.0 \times 10^{-6} \mathrm{~m}^{3} \mathrm{~s}^{-1}\right)$ was chosen to be sufficiently small so that the evolution of the mean salinity in the tank was slow compared with the rate of overturning.

The timescale $t_{\mathrm{c}}$ on which the convection ventilated the entire volume of the box by passing water through the bottom boundary layer is

$t_{\mathrm{c}}=V / q$,

where $q$ is the volume transport through the boundary layer and $V$ is the total volume of the box. Using the scaling analysis from MGH04, in which the boundary-layer thickness $h \sim L R a_{F}^{-1 / 6}$, horizontal velocity $u \sim \kappa_{T} R a_{F}^{1 / 3} / L$ and volume flux $u h W \sim \kappa_{T} W R a_{F}^{1 / 6}$, the ventilation time is given by

$t_{\mathrm{c}} \sim \frac{V}{u h W} \sim \frac{V R a_{F}^{-1 / 6}}{\kappa_{T} W}$.

In these experiments, $t_{\mathrm{c}} \sim 7000 \mathrm{~s}$. The timescale on which the tank volume was flushed by salt water input and sink withdrawal is $t_{\mathrm{f}} \sim V / Q \sim$ $23000-427000 \mathrm{~s}$. The ratio of the ventilation and flushing timescales for the experiments ranged over

$\frac{t_{\mathrm{c}}}{t_{\mathrm{f}}} \sim \frac{R a_{F}^{-1 / 6} Q}{\kappa_{T} W} \sim 0.017-0.28$,

with values most commonly around 0.03 . Hence, the salinity anomaly of the source decreased by $\sim 3 \%$ in each ventilation time.

The injection of the salt solution was halted once the flow circulation pattern had been clearly established for some time. The experiment was then generally continued with (unchanged) thermal forcing alone until the salt concentration was homogenized throughout the tank and the flow had returned to the initial full-depth overturning.

\subsection{Measurements and visualization}

In most runs, qualitative observations of the flow were made using a shadow-graph set-up. Three vertical tubes in the lid (Fig. 3) were used for adding potassium permanganate crystals into the flow to produce vertical dye lines. The subsequent deformation of the dye lines provided information on the horizontal velocities in the flow.

Time series of temperature was provided by eight fast-response thermistors held at fixed positions in the tank (Fig. 3). In the second tank, two additional thermistors were embedded within the copper base close to its surface at $x=0.1$ and $1.15 \mathrm{~m}$. The thermistors were attached to a rack above the tank and vertical profiles of temperature were obtained by logging while traversing. Each traverse ran from the lid to $2 \mathrm{~mm}$ above the base. The speed of
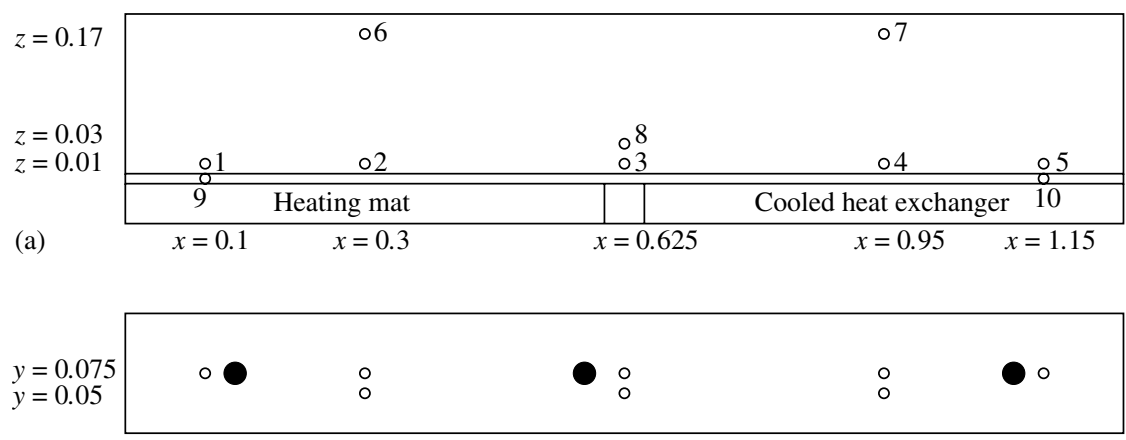

(b)

Fig. 3. Thermistor and dye tube positions in the second tank. (a) Side view and (b) plan view. The open circles show the thermistor positions and the larger black circles show the location of dye tubes. Positions are shown as distance $x(\mathrm{~m})$ from the left end, and height $z$ (m) above the base. 
traverse was $6.1 \mathrm{~mm} \mathrm{~s}^{-1}$. Samples were taken at a rate of 60 samples s $^{-1}$ and averaged over a window of five samples to reduce instrumental noise, giving a spatial resolution of $\sim 0.5 \mathrm{~mm}$.

All salinities were determined by measuring the density of samples to an accuracy of $\mathrm{O}\left(10^{-2}\right) \mathrm{kg} \mathrm{m}^{-3}$ at $20.00 \pm 0.01^{\circ} \mathrm{C}$ using an Anton Paar densimeter. The salinity distribution in the tank was also visualized using an in situ optical absorption technique. The salt solution was coloured with a known amount of green dye and the dye concentration $C_{\text {dye }}$ was calculated by measuring the attenuation of the intensity of incident light as it passes through the dyed solution compared to an undyed reference state (Cenedese and Dalziel, 1998). The concentration of dye can be used as a proxy for salt concentration. Although the molecular diffusivities of dye and salt are different, dye concentration is expected to be proportional to salinity in the present experiments because mixing in the flow and across density interfaces occurs mainly by turbulent processes. However, measurements in the vicinity of density interfaces and strong density gradients may be inaccurate because of the focussing or defocussing of incident light by refractive index gradients. Additional details of the measurement technique are given in Mullarney (2004).

\section{Experimental results}

\subsection{Thermally forced circulation}

We first give a brief description of the circulation arising from the thermal forcing alone. Further details of this flow, along with two-dimensional numerical solutions, are given in MGH04. The large-scale thermally forced overturning was twodimensional. Water in a boundary layer above the cooled half of the base was cooled towards the imposed boundary temperature at a rate equal to the imposed rate of heat supply through the other half of the base. The cold water flowed towards the heated end of the box, where the boundary-layer stratification was eroded from beneath by smallscale three-dimensional convection (Fig. 4). A theoretical solution based on encroachment of the convection into the stable overlying boundary-layer stratification provides a good description of the measured CML thickness (MGH04). At the end of the box, the mixed layer encompassed the entire boundary layer, the mass flux of which fed directly into a plume against the endwall. The plume ascended to the top of the box and formed an outflow along the upper boundary. The outflow featured large eddies that occupied approximately a third to one-half of the box depth and travelled

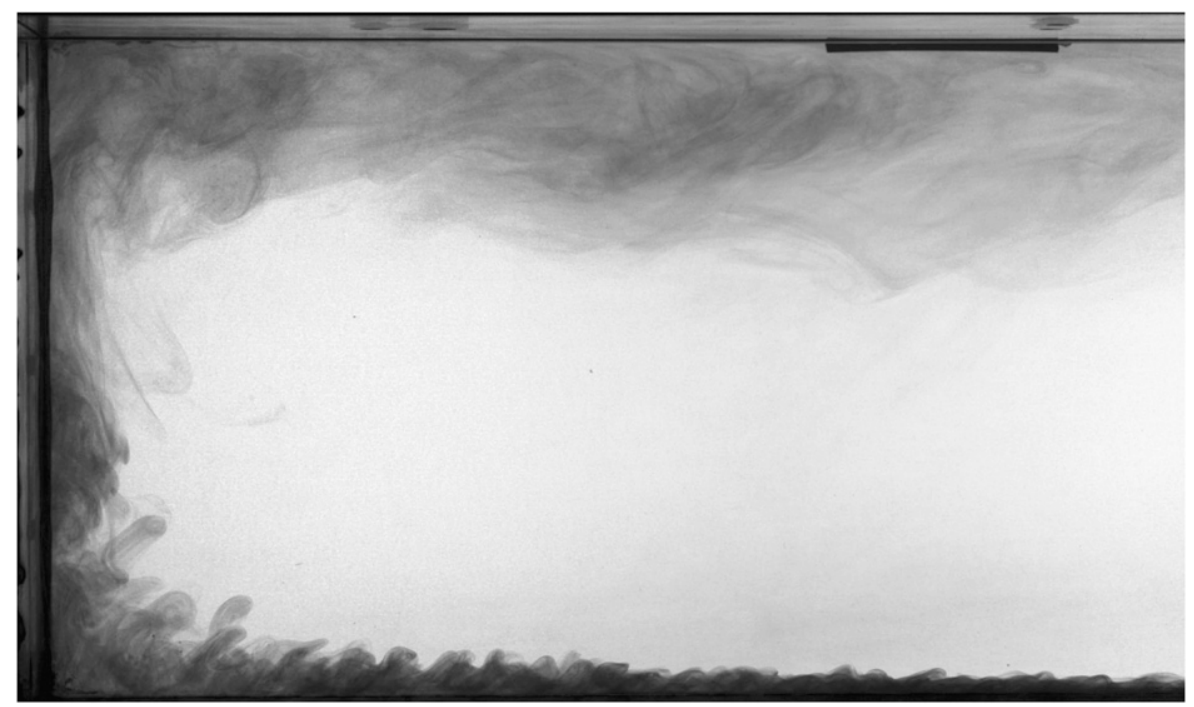

Fig. 4. Photograph of the thermally equilibrated flow (before the introduction of the salt source) showing the 'convective mixed layer' marked by dye along the base, the turbulent upwelling plume against the endwall and the eddying plume outflow. The image shows the full depth of the tank and a section over the heated half of the base spanning approximately $0.35 \mathrm{~m}$ from the left-hand endwall. The neutral density dye tracer was released from a vertical tube at the centre of the tank into the bottom boundary layer. It does not reveal the stably stratified portion of the boundary layer above the mixed layer. Total power applied to the heating mat was $270 \mathrm{~W}$. 
slowly along the length of the box. The circulation was closed by a weak downwelling. Temperature profiles revealed a very weak stratification throughout the box depth above the boundary layer (buoyancy frequency $N \sim 5 \times 10^{-2} \mathrm{~s}^{-1}$ for $\left.q=140 \mathrm{~W}\right)$. In contrast, the strongly stratified boundary layer for the same heat flux had $N \sim 2 \mathrm{~s}^{-1}$.

\subsection{Steady flow at small buoyancy flux ratios}

For small buoyancy flux ratios $B_{S} / B_{T}$, the largescale deep overturning established by the thermal forcing was little affected by the introduction of the saline solution. The source solution quickly formed a thin layer of depth $10-20 \mathrm{~mm}$ at the base and between 50 and $150 \mathrm{~mm}$ in length. The oncoming flow in the boundary layer was lifted above the interface of the denser salt layer. We refer to this behaviour as regime I. A detailed dynamical analysis of the salt layer evolution indicates that a balance operates between buoyancy, inertia of the oncoming boundary-layer flow and stress on the upper interface of the saline layer (Mullarney, 2004). Although we refer to the 'salt layer', it was at times observed to consist of several vertically stacked convecting layers separated by doublediffusive interfaces. The stabilizing salt concentration allowed temperatures within the salt layer to be greater than all other temperatures in the tank. Heat and salt were carried across the interface into the interior, maintaining a steady state (apart from the gradual addition of salt to the whole tank volume). In the interior there was both a horizontal gradient and an unstable vertical stratification in salinity, maintained by the continuous increase of average salinity with time. Note that temperature dominated the bulk vertical stratification and maintains a stably stratified interior. The thermal boundary layer over the cooled base was therefore of a lower salinity than the interior water. Hence, the boundary layer (thermocline) had conditions favourable for the formation of salt fingers, although there was no evidence of fingering in this regime.

Once the salt layer had reached its maximum length, the flow appeared to be in a quasi-steady state. Small variations in the length and shape of the salt layer persisted with intermittent flattening or steepening of its leading edge and a movement of the uppermost interface away from or towards the endwall in the face of the oncoming boundary-layer flow. The upper layers were always driven towards smaller stability ratios $R_{\rho}=\beta \delta S / \alpha \delta T$, where $\delta S$ and $\delta T$ are the salinity and temperature differences across the uppermost density interface. Hence, the top salt layer intermittently broke away from the halocline (when $R_{\rho} \sim 1$ ) and was swept upwards in the plume. Despite the salt transport, the plume continued to rise strongly to the top of the tank (although the plume was wider than in the purely thermally forced flow). The salt was carried along the top of the box by the plume outflow, but had no measurable effect on the time-averaged temperature distribution anywhere in the tank except in the salt layer.

\subsection{Oscillatory regime}

At somewhat larger rates of salt injection the flow underwent marked oscillations, with repeated growth and breakdown of the salt layer (regime II). This differs from regime $I$ in that it involved unsteady breakaway of a substantial portion of the salt layer and caused measurable fluctuations in distant parts of the circulation.

Fig. 5 shows the evolution of the salinity anomaly field (relative to the initial salinity in the tank) through the first cycle in an experiment from this regime. After its initial growth and warming (Fig. 5a), the salt layer remained at a nearly constant temperature until the first breakdown. Hence, heat gained from the base was lost through the interface at an approximately equal rate, with both the gain and loss being dependent on the length of the layer. In contrast, the salt was added at a constant rate, but was lost through the interface at an increasing rate as the layer lengthened. The layer grew to a maximum length, which remained fixed for a time while the layer thickened. When $R_{\rho}$ approached one, the nose steepened, and the layer shortened and began to break away into the overlying flow. The sequence of images in Fig. 5b-f shows the layer breakaway and the movement of the salt through the interior. Although most of the saline water released by the rapid overturn was carried to the top of the box and along the top in the plume outflow, a small amount remained relatively dense compared to the interior water and intruded into the ambient stratification above the boundary layer (as indicated by the more saline tongue in images in Fig. 5d-f). Most of this intermediatedepth intrusion was subsequently entrained back into the plume and carried to the top (Fig. 5e and f). During the breakdown of the salt layer the plume 
(a)

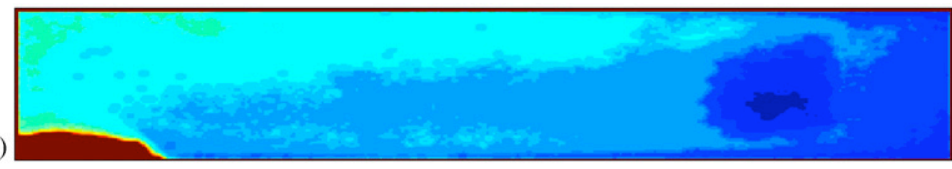

(b)

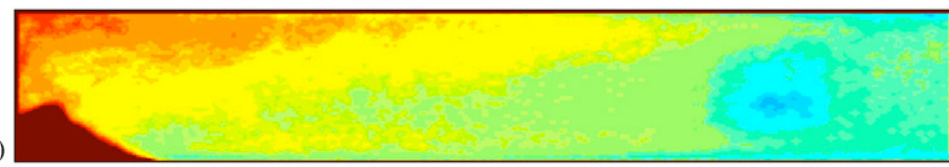

(c)

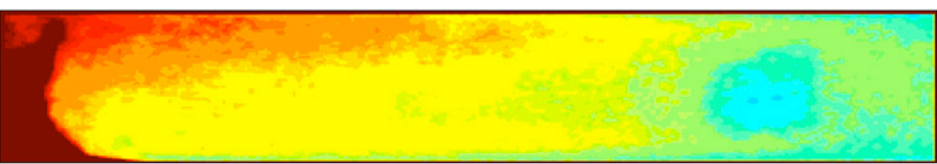

(d)

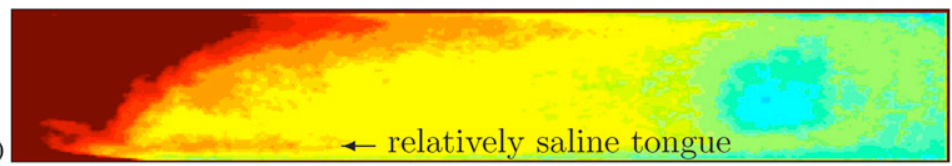

(e)

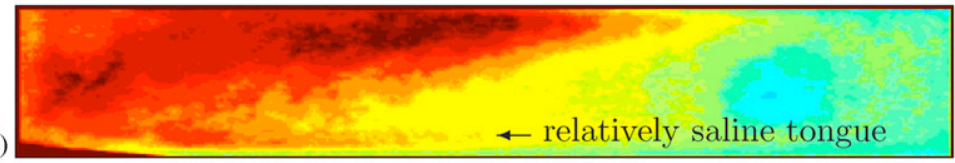

(f)

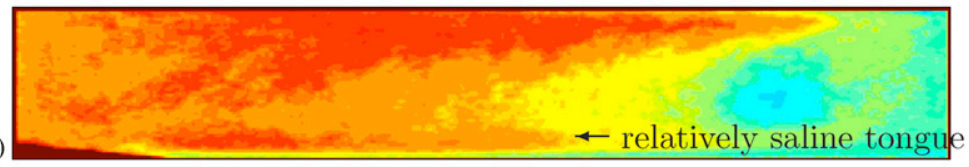

$10^{4} \times \beta \Delta S$

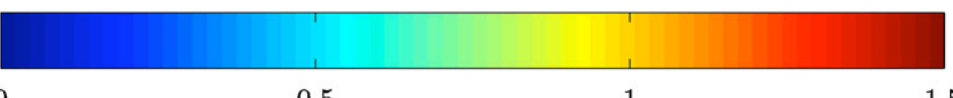

0

0.5

1

Fig. 5. Evolution of the salinity field in an experiment which exhibited oscillatory behaviour $\left(R a_{F}=1.5 \times 10^{14}, B_{S} / B_{T}=0.049\right.$ and $P e=7)$. The scale has been chosen to reveal the perturbation to the interior salinity field as the salt layer broke down, hence the salt layer salinity is off-scale. Images were taken at times (in minutes after turning on the source input): (a) 100, (b) 122, (c) 126, (d) 130, (e) 134 and (f) $138 \mathrm{~min}$. The apparent salinity anomaly in the right-hand $25 \%$ of the tank is, in part, a result of a bright area on the image that was not fully removed upon comparison with a reference image taken before salt injection began.

was again much wider than in the purely thermally forced overturning.

Sequential formation of a stack of double-diffusive layers near the source appeared to play a role in the breakdown process. As the salt layer deepened and was held against the endwall by the oncoming boundary-layer flow, a new salt layer only a few millimetres thick appeared at the base, with the two layers separated by a diffusive interface. The bottom salt layer eventually extended to the same length as the overlying salt layer and, during this period, most of the salt from the source was fed into the new bottom layer. Thus, the top layer was no longer stabilized by direct salt input, but continued to lose salt increasingly rapidly through the weakening uppermost diffusive interface. The density ratio across this interface decreased $\left(R_{\rho} \rightarrow 1\right)$ until the top salt layer was swept away by the large-scale circulation. The bottom layer thickness grew to approximately $10-20 \mathrm{~mm}$ and the cycle repeated.

Temperature-time records are shown in Fig. 6 for another experiment (with approximately the same parameters as that in Fig. 5) that exhibited oscillatory behaviour. In this case the heating and cooling at the base were applied for approximately $28 \mathrm{~h}$ before the salt flux was initiated (at $t=0$ in Fig. $6)$. In this plot the time has been normalized by the ventilation timescale $\left(t_{\mathrm{c}}=7290 \mathrm{~s}\right.$ from Eq. (4)). The temperatures $T_{\mathrm{e}}$ have been converted to a dimensionless temperature $\hat{T}$ defined as

$$
\hat{T}=\left(T_{\max }-T_{\mathrm{e}}\right) / \Delta T,
$$




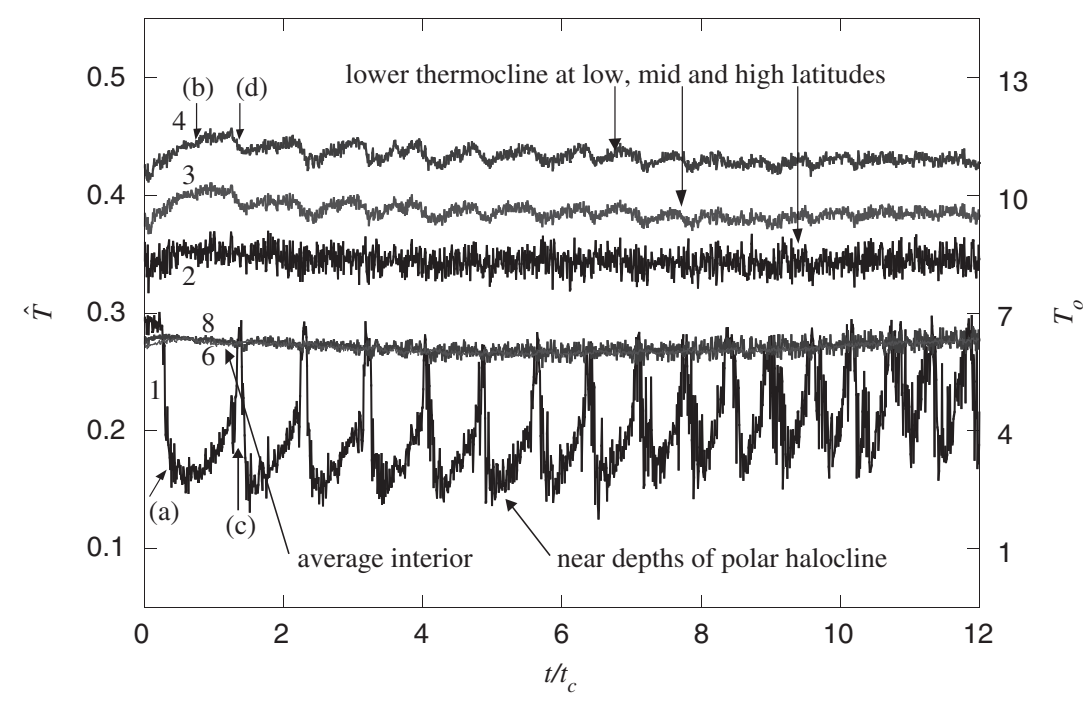

Fig. 6. Dimensionless temperature $\hat{T}$ record from stationary thermistors in an experiment with $R a_{F}=1.5 \times 10^{14}, B_{S} / B_{T}=0.048$, $P e=7.5$. Thermistor numbers correspond to the locations in Fig. 3. Thermistors $1-4$ were in the boundary layer; thermistor 6 was in the interior and thermistor 8 was slightly above the thermal boundary layer at the midpoint of the box. The record from thermistor 5 (omitted) was similar to that from 4 , and the record from thermistor 7 (omitted) was identical to that from 6 . Each data point is an average of six measurements, sampled at 10 s intervals. Letters indicate changes in the flow conditions discussed in the text. Eq. (6) was used to calculate $\hat{T}$, with $T_{\max }=37.98^{\circ} \mathrm{C}$ and $T_{\min }=16.38^{\circ} \mathrm{C}$. The scale on the right-hand axis is an estimate of the predicted ocean temperature.

where $\Delta T=T_{\max }-T_{\min }$ is the difference between the maximum and minimum boundary temperatures.

This non-dimensionalization relates temperature fluctuations and spatial differences to the overall temperature difference along the base. The sign convention also relates the measurements in the (inverted) laboratory experiment to a frame of reference with forcing applied at the upper surface: thus a decrease in $\hat{T}$ represents both warming at a given point in a box with basal forcing and cooling at an equivalent position with relation to thermal forcing applied at the top boundary (or ocean surface) - the correspondence is exact for a linear equation of state. Extrapolation of the laboratory results to the ocean is then possible. For the surfaceforced ocean $\hat{T}=\left(T_{\mathrm{o}}-T_{\min }\right) / \Delta T$, where $T_{\mathrm{o}}$ is the local ocean temperature (right-hand scale in Fig. 6), $T_{\min }$ is the minimum surface temperature and we have taken $T_{\min }=-2{ }^{\circ} \mathrm{C}$ and $T_{\max }=28^{\circ} \mathrm{C}$, giving $\Delta T=30^{\circ} \mathrm{C}$. We discuss below the laboratory temperature records in terms of the ocean orientation, in order to highlight some of the mechanisms that may play a role in causing temperature fluctuations in the ocean, while recognizing that the laboratory conditions (specifically the range of Rayleigh number and the absence of planetary rotation and surface wind stress) might not satisfactorily mimic ocean conditions.

As the halocline deepened and covered thermistor 1, the stabilizing influence of the surface freshwater input (in the ocean orientation) can be seen by the sudden decrease in $\hat{T}$ at (a). The fresher layer partially blocked the boundary-layer flow, causing the thermocline to thicken and $\hat{T}$ (at a fixed depth within the thermocline) to increase (thermistors 3 and 4 , at (b)). This increase was more pronounced for larger $B_{S}$ (deeper or longer intruding layer). This observation is consistent with no measurable thickening of the thermocline in regime I (Section 4.2), as substantial blocking of the boundary-layer flow will occur when the freshwater layer is thicker than the (unperturbed) CML (i.e. extending to depths of the stable thermocline stratification) at the location of the leading edge of the fresh intrusion. As the halocline became less stable and vertical mixing increased, thermistor 1 began to detect an increase in $\hat{T}$. When the halocline broke down (c), there was a more rapid increase in $\hat{T}$. The overturning also caused a rapid thinning (d) of the thermocline along the whole length of the box, and there were interior fluctuations of dimensionless temperature $\hat{T}$ on the order of 0.005 (corresponding to order $0.1^{\circ} \mathrm{C}$ in the laboratory). 
The cyclic behaviour continued until the salinity input was stopped (after $24 \mathrm{~h}$ of oscillations, $t / t_{\mathrm{c}} \approx 12$ ). The interior temperature (thermistors 6 and 8) showed an initial slow decrease in $\hat{T}$ (approximately $0.5^{\circ} \mathrm{C}$ ) over the first seven cycles, possibly owing to the long timescale for the interior to adjust to the perturbed boundary condition. However, this interior response was not detectable in all runs. The slow long-term decrease of the oscillation period and amplitude seen in Fig. 6, along with a gradual decrease of $\hat{T}$ in the thermocline, was a result of the net addition of salt to the tank interior, which reduced the salinity anomaly $\Delta S$ of the source water with time. For the experiment shown in Fig. 6, the salinity anomaly is estimated to have decreased by $34 \%$ over the duration of the experiment $(\beta \Delta S=0.00285-$ 0.00187).

Consistent with the dependence of oscillation period on the evolving salinity anomaly, runs with smaller initial $\Delta S$ gave shorter oscillation periods. Some runs also exhibited less regular behaviour with greater variability in period, amplitude and shape of the cyclic temperature record.

\subsection{Intermediate-depth intrusion regime}

For moderate values of the salt input rate, the salt layer intruded further over the heated plate towards the cooled half of the base. However, before it reached the cooled base, the nose of the salt layer lifted off the base and formed an intrusion above the stable boundary layer (regime III). By analogy, this process would correspond to the subduction of cold fresh surface water in the mid- to high-latitude oceans, forming an equatorward intrusion beneath the warm and salty thermocline. Fig. 7 shows a sequence of diagrams illustrating the development of the flow in this regime. The spreading of the salt layer was initially rapid (Fig. 7a) and then halted.
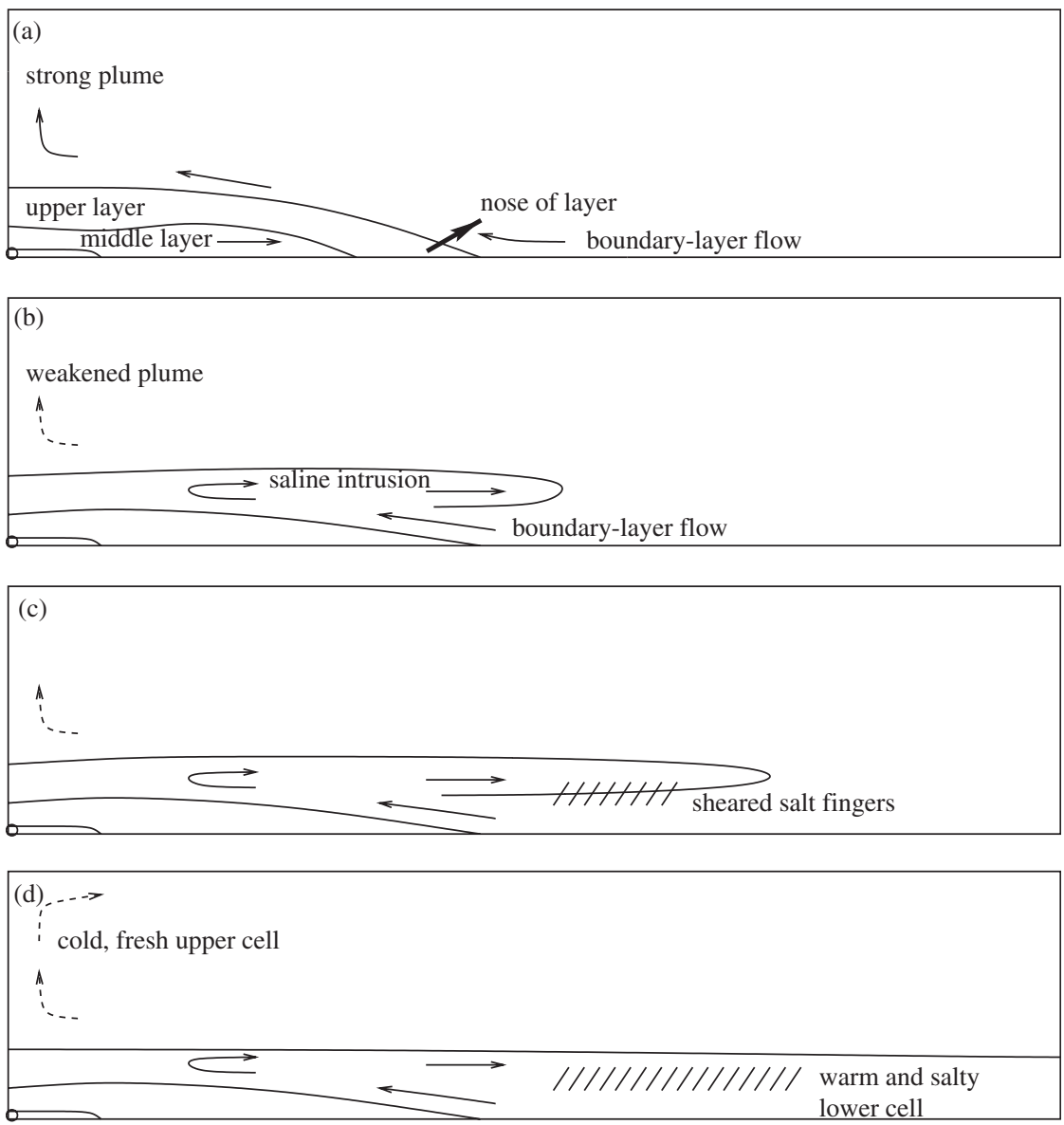

Fig. 7. A sequence of schematic illustrations showing the evolution of the salt layer in those experiments where it lifts off the base to form a relatively warm and salty intrusion above the thermal boundary layer (regime III). 
The layer thickened and formed intermediate layers, as revealed by the temperature and salinity profiles (Fig. 8). The stability ratio across the uppermost interface in the profile at $x=0.1 \mathrm{~m}$ is $R_{\rho} \approx 2$. Temperature and salinity within the layers decreased with distance from the source and mixing was active in the nose region of the layer.

Gradually, the nose region of the layer was destabilized by virtue of the increasing length of interface through which salt was lost, and the layer retracted by $10-20 \mathrm{~mm}$ in the face of oncoming flow.
Eventually, the nose lost sufficient salt (despite decreasing in temperature with distance from the source owing to the loss of heat to the water above) to rise off the base (Fig. 7b) and become an intrusion above the thermal boundary layer. As a result of being above the boundary-layer flow, the intrusion propagated more rapidly and further along the box. However, the rate of propagation was slowed somewhat by salt fingering, which caused the salinity and the temperature anomalies to decrease with distance. Sheared salt fingering was
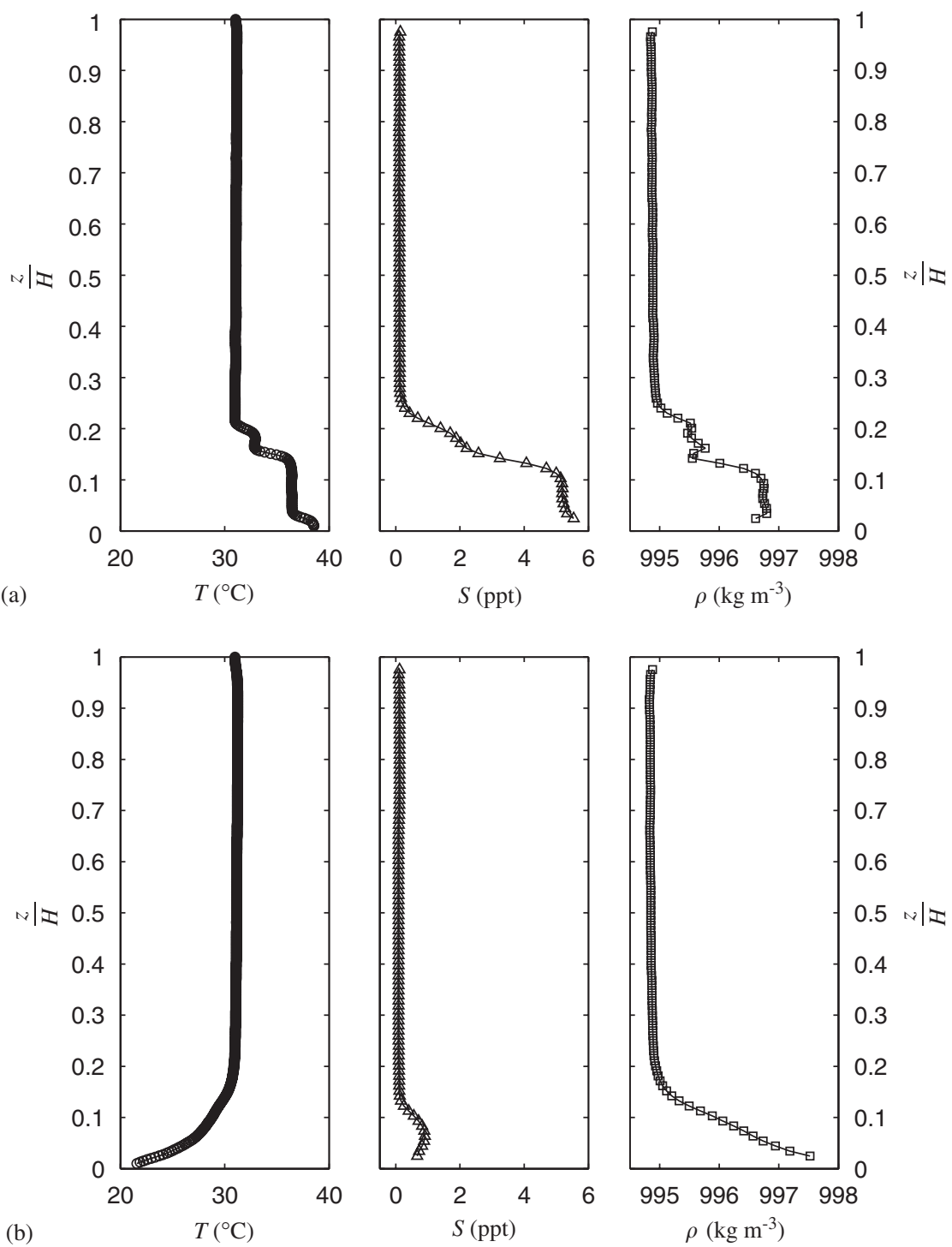

Fig. 8. Vertical temperature, salinity and density profiles from an experiment in the thermocline intrusion regime III. The profiles were from (a) $x=0.1$ and (b) $0.625 \mathrm{~m}$ taken at $2 \mathrm{~h} 10 \mathrm{~min}$ after the start of the input of the salt solution. At this time the more saline water had formed an intrusion above the cold fresh boundary layer and extended to $x=0.69 \mathrm{~m}$. The vertical resolution of the salinity interfaces may be limited by the measurement technique, which gives an integral across the box width. 
visible in much of the boundary layer, while the interface between the interior water and the intrusion was stratified in the diffusive sense. The profiles shown in Fig. $8 \mathrm{~b}$ reveal the intrusion salinity maximum at the midpoint in the box $(x=0.625 \mathrm{~m})$. At this stage (Fig. 7c) the endwall plume was weak and most of the boundary-layer mass flux was returned towards the cooled end of the box within the new intrusion.

In some runs the boundary layer eventually broke through the salt layer structure and reestablished the initial conditions with an endwall plume and fulldepth overturning. Several repeated cycles ensued (up to seven were observed), with each cycle involving a weakening of the endwall plume and often the formation of a new intrusion above the boundary layer. However, for all experiments in this regime, a continued source input eventually led to a two-cell circulation and stable layering across the full length of the tank (Fig. 7d). There was a strong recirculation in the lower cell. Circulation in the upper cell, driven only by the diffusive flux of heat through the interface from the lower cell, was weak and in the same sense (rising and sinking at the heated and cooled ends, respectively) as that in the lower cell. Very small convective plumes formed on each side of the doublediffusive interface between the cells and were swept along with the large-scale circulation.
Continued source input led to the formation of additional layers at the bottom. However, in most experiments the salt injection was switched off once two-cell circulation was established. The flow was then left to evolve with thermal forcing alone. Shortly after the source was turned off, the most recently formed salt layers near the source (shown in Fig. 7 d) overturned (on a timescale of $\sim 30 \mathrm{~min}$ ) and mixed throughout the lower cell. The two-cell circulation persisted for periods of $\sim 5-60 \mathrm{~h}$ before eventually overturning, whereupon the flow returned to a full-depth, single cell circulation with a uniform salinity.

Fig. 9 shows the dimensionless temperature record from an experiment in the intrusion regime with a buoyancy flux ratio $B_{S} / B_{T}=0.080$. The initial deepening of the halocline is shown by thermistor 1 in Fig. 9 at (a) and illustrated in Fig. 7a. The first breakdown of part of the halocline occurred at (b), when some of the warm and salty (relatively cold and fresh in the ocean) water formed an intermediate-depth intrusion (shown in Fig. $7 \mathrm{~b}$ and corresponding to a short cooling episode at thermistor 8 at (c) in Fig. 9). A larger intermediatedepth intrusion formed on the subsequent breakdown (see (d) in Figs. 9 and 7c). The deepening of the halocline in each cycle caused substantial thickening of the boundary layer along the full

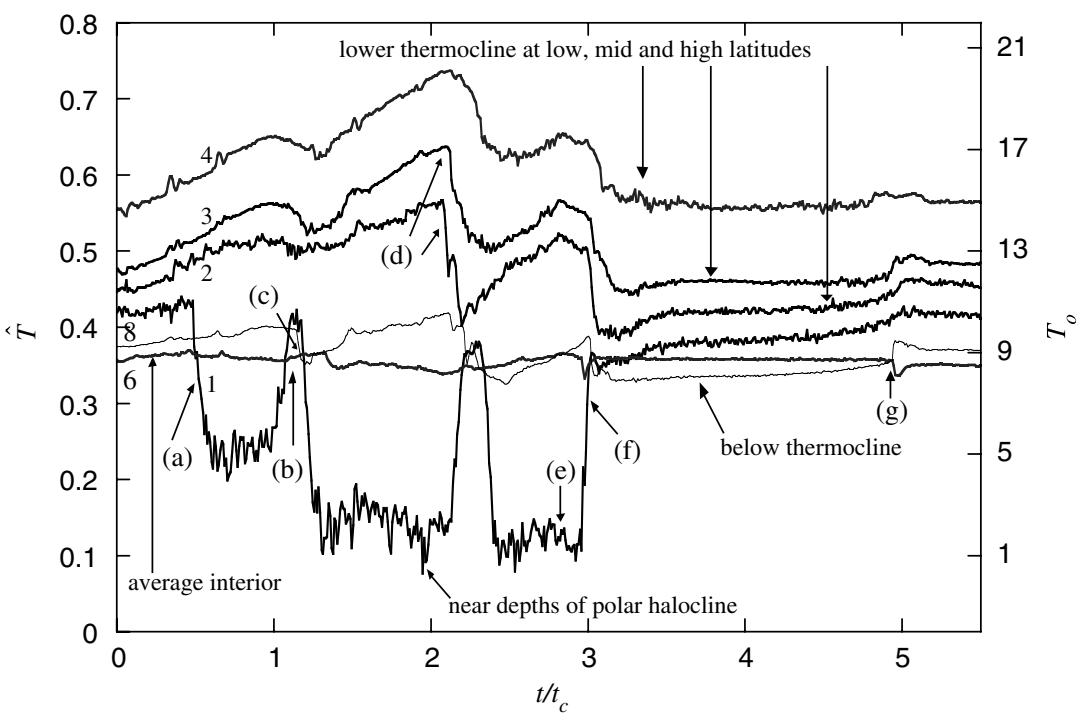

Fig. 9. Dimensionless temperature $\hat{T}$ record from stationary thermistors in an experiment with $R a_{F}=2.07 \times 10^{14}, B_{S} / B_{T}=0.08, P e=4$. Thermistor numbers correspond to the locations in Fig. 3 (see also caption of Fig. 6). Each data point is an average of six measurements, sampled at $10 \mathrm{~s}$ intervals. Letters indicate changes in the flow conditions discussed in the text. Eq. (6) was used to calculate $\hat{T}$, with $T_{\max }=43.6^{\circ} \mathrm{C}$ and $T_{\min }=30.4{ }^{\circ} \mathrm{C}$ (measured at thermistors 1 and 5 , at $1 \mathrm{~cm}$ above the base). The scale on the right-hand axis is an estimate of the predicted ocean temperature. 
length of the box, and the breakdown of the halocline (with formation of an intrusion) led to rapid thinning of the thermocline (after (d)) at thermistors 2, 3 and 4 . The intrusion reached the far endwall at (e) (Fig. 7d). The salt injection was switched off at about the same time as the third breakdown of the halocline. At (f) the remaining layering near the source overturned, leaving a twolayer circulation involving a shallow cell extending the full length of the box adjacent to the heated and cooled boundary and a deep slowly circulating cell. The two cells eventually overturned at (g).

\subsection{Flooding regime}

For very large rates of salt input, the salinity anomaly spread directly along the base (regime IV). As the salt layer lengthened, it lost salt at a greater rate through its increased interfacial area, leading to a decrease in the density difference that forced propagation of its leading edge. Hence, the rate of lateral spreading slowed. However, once the leading edge of the salt layer reached the cooled portion of the base, at $x>L / 2$, the driving density difference began to increase again owing to the cooling. Consequently, lifting-off of the layer as seen in regime III could no longer occur. Sheared salt fingers formed within the layer and were maintained by the heat and salt fluxes and recirculation within the layer. The salt layer eventually flooded the entire base (after approximately 1-2 ventilation times) forming a stable two-cell circulation. Once the lower circulation cell was established, it accommodated the imposed horizontal heat transport as well as the return mass flux matching the boundary-layer flow. Convection and horizontal heat transport were almost entirely confined within the shallow salty layer. The lower cell was separated from the remainder of the water column by a sharp interface of the diffusive type above the heated half of the base, and by a doubly stable interface above the cooled end. The interface sloped down to the right above the heated base, whereas it was close to horizontal above the cooled plate. The depth of the lower cell increased with time at a rate given by the salinity source volume input. After the source input was turned off, the interface became nearly horizontal and the layer deepened more slowly. Eventually the layers in the box overturned as $R_{\rho}$ decreased towards unity.

Soon after the salinity source was turned on, but prior to reaching the two-cell state in the flooding regime, a temporary cessation of the full-depth convection was usually observed. The initial salinity buoyancy flux out of the halocline weakened the thermally driven plume so that convection no longer penetrated the full depth of the box. In experiments the depth of the overturning reduced to around $z=0.06 \mathrm{~m}$. This created a (relatively weak) density interface on which small eddies and plumes were visible. The layer below this interface was fed by the plume outflow, but deepened by encroachment until the endwall plume again penetrated to the top of the tank. Throughout the experiment, the plume near the left-hand endwall was much wider than that in the circulation driven by thermal forcing alone (Section 4.1).

\subsection{Regime boundaries}

We recall from Section 2 that the governing parameters are $R a_{F}, B_{S} / B_{T}, P e, P r, \tau$ and $A$, of which we focus on the dependence of the flow upon $B_{S} / B_{T}$. Over the range of $R a_{F}$ considered, the results of MGH04 show that the thermal convection is dynamically similar. As noted in Section 2 we do not expect the variation of $P e$ to be important, and we check this assumption here. For each of several heat fluxes, a range of buoyancy flux ratios $B_{S} / B_{T}$ was achieved by varying both $\beta \Delta S$ and $Q$. Both the flux Rayleigh number $R a_{F}$ and the thermal buoyancy flux $B_{T}$ were evaluated using the effective heat input $F_{T} L W / 2$, defined as the total power provided to the heating mat less the heat lost to the room. The regime classification of each experiment is shown in Fig. 10 in terms of the input rates of thermal buoyancy and salinity buoyancy. Fig. 11 places the same results in terms of the ratio of salinity to thermal buoyancy inputs and the dimensionless inflow rate of the salt source (as measured by a Péclet number $P e$ ). Experiments with large source volume fluxes $\left(Q>5 \times 10^{-7} \mathrm{~m}^{3} \mathrm{~s}^{-1}\right)$ have been omitted because they appeared to be influenced by enhanced mixing owing to the momentum of the solution injected at the source.

Although each experiment has been classified into one of four regimes, some runs exhibited either transient behaviour characteristic of a different regime or behaviour transitional between two regimes. In particular, the experiments in which the warm saline intrusion formed above the thermocline with a cyclic breakdown of the salt layer have been classified as the intrusion regime (III) rather than the oscillatory regime. Cases in 


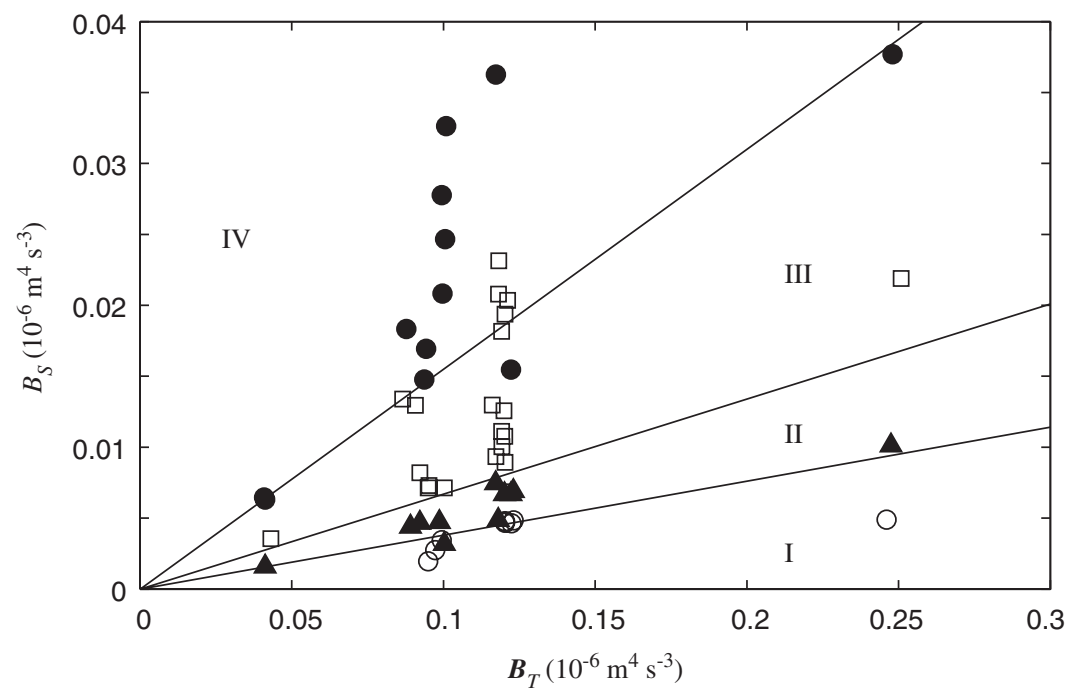

Fig. 10. Classification of flow regimes plotted in terms of salinity buoyancy input and thermal buoyancy input rates. $\bullet-$ flooding regime (IV), $\square$-intermediate intrusion regime (III), $\boldsymbol{\Delta}$ - oscillatory regime (II) and o-quasi-steady regime (I). The lines shown serve as reasonable boundaries between regimes and are at $B_{S} / B_{T}=0.038,0.067$ and 0.155 .
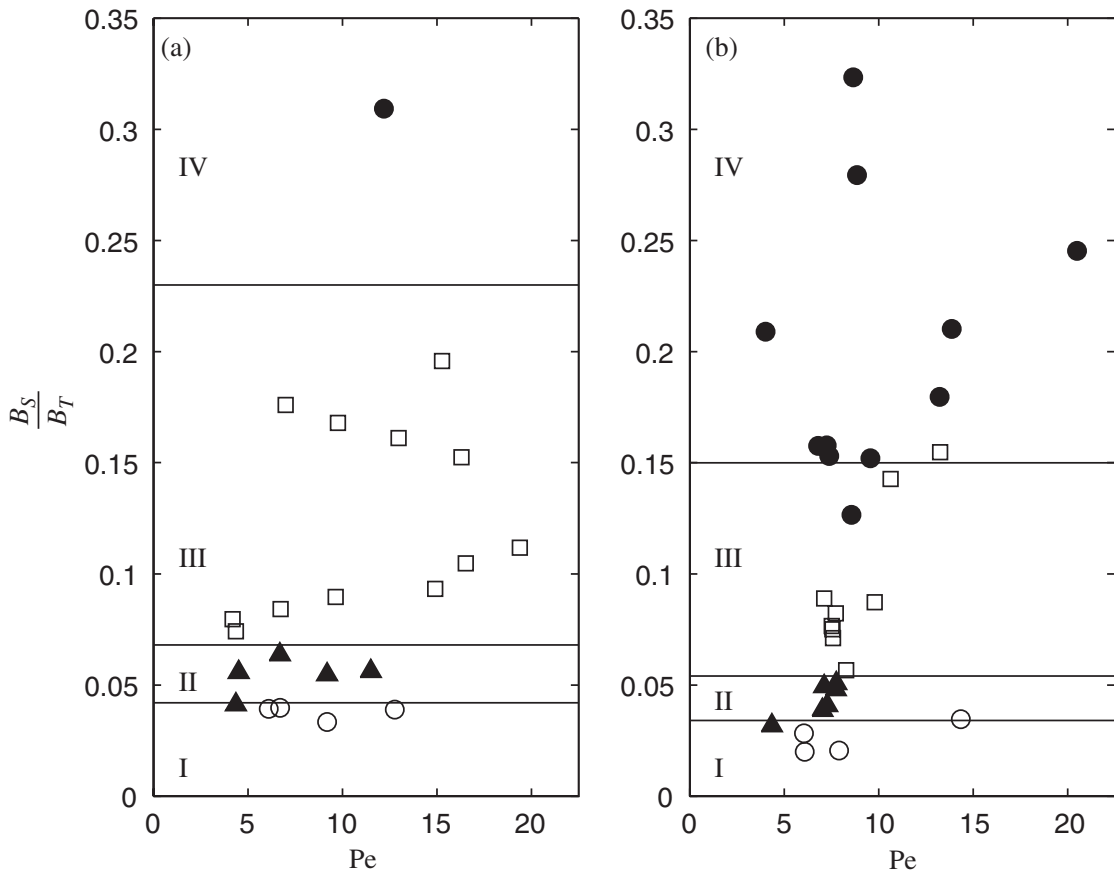

Fig. 11. Classification of flow regimes plotted as a function of the ratio of buoyancy inputs and dimensionless volume inflow rate. The results are subdivided into (a) the first (glass) tank and (b) the improved second tank. The regimes are as in Fig. 10. The boundaries shown between regimes are at $B_{S} / B_{T}=0.042,0.068$ and 0.23 in (a) and $B_{S} / B_{T}=0.034,0.054$ and 0.15 in (b). When both sets of results are included on a single graph, reasonable boundaries for the lower two transitions are given by $B_{S} / B_{T}=0.038$, 0.067 , whereas the transition to the flooding regime is apparently more sensitive to thermal boundary conditions.

which a cyclic breakaway of some of the salt layer (regime II) gradually decreased in magnitude until the flow formed a quasi-steady layer near the source (regime I) have been classified in the oscillatory regime (II) based on the observed behaviour for the initial buoyancy fluxes.

The straight lines in Fig. 10 show that the flow regime depends on both the thermal and salinity 
buoyancy fluxes, and that transitions are approximately described by fixed values of the ratio $B_{S} / B_{T}$. Although $B_{S}$ depends on both $\beta \Delta S$ and $Q$, Fig. 11 confirms that our results indicate no clear dependence on the Péclet number $P e$. The lower two transition boundaries in Fig. 11 occur at only very slightly larger values of $B_{S} / B_{T}$ in the first tank than in the second tank and the differences are not significant. The upper transition to the flooding regime occurred at a larger flux ratio in the first tank and we attribute this difference to the different boundary condition over the cooled half of the base: the base temperature was not uniform in the first tank, leading to lift-off of the leading edge of the salt layer over the cold base and formation of intermediate intrusions at larger values of $B_{S} / B_{T}$.

\subsection{Double-diffusive effects}

Although double-diffusive molecular effects are inherent to thermohaline convection, and hence to large-scale ocean circulation, their role in the oceans may be reduced by turbulent mixing relative to laboratory experiments. In order to examine the effects of removing double-diffusive processes, we carried out experiments in which the stabilizing buoyancy flux was provided by an input of relatively cold water in place of the saline water source. The set-up for these experiments was the same as that shown in Fig. 2, except that the constant temperature bath, through which the source water was passed, was maintained at a lower temperature. Both source and tank water were fresh and dye was added to the source water. In these experiments, the ratio of stabilizing to destabilizing buoyancy fluxes is given by

$\frac{B_{T}^{\text {source }}}{B_{T}}=\frac{2 \rho_{0} c_{p} \Delta T Q}{F_{T} L W}$,

where $\Delta T=T_{\text {source }}-T_{0}$ is the temperature difference between the source water and the average interior temperature (the latter being very close to the hottest temperature in the box). The range of flux ratios $0.011 \leqslant B_{T}^{\text {source }} / B_{T} \leqslant 0.335$ was used. The addition of cold source water implies that there will be an equilibration time (of at least $24 \mathrm{~h}$ ) during which there is a net extraction of heat from the box.

For small values of the flux ratio, the cooled water did not accumulate at the source and was instead incorporated into the large-scale circulation, which remained as a single cell occupying the full depth of the box. However, some of the basal input heat flux now warmed the cool source water directly. The net heat input was in effect reduced. Hence, the mass flux in the circulation was reduced. This behaviour is identical to that observed with a small stabilizing buoyancy flux from a source of salinity. A transition in flow regimes occurred when the ratio of buoyancy fluxes was close to $B_{T}^{\text {source }} / B_{T}=0.1$. For source fluxes larger than this, the introduction of the cold water had a rapid and dramatic effect on the large-scale overturning. Both dye tracer and temperature profiles showed that relatively cool water from the source pooled at the heated end of the base next to the endwall. This region soon reached a maximum length and thereafter remained almost stationary, with only a very slow anticlockwise circulation within. There were no sharp refractive index (density) interfaces. This pool was continually replenished with cold source water, while also being continually heated from below, and remained more dense than the oncoming boundary layer. In contrast to the experiments with a salinity flux, the oncoming boundary layer did not flow over the top of the region of source water. Rather, it flowed directly upwards from the base in a series of small plumes near the leading edge of the source water. There was no evidence of the turbulent plume seen in both the purely thermal convection and in the thermohaline experiments. The small plumes did not have sufficient buoyancy to rise to the top of the tank, so that most of the bottom boundary-layer mass flux ascended through only a fraction of the depth before being incorporated into the interior. Once this partial-depth convection commenced, a positive feedback became apparent: the lower cell (containing the cold pool) cooled at a faster rate than the upper cell as a result of the still unbalanced net cooling from the base and the source. The upper cell involved only very slow motion, presumably driven by a horizontal temperature gradient set up by diffusion from the lower cell. The depth of the lower cell was reduced when the stabilizing forcing from the source was larger. There was a larger (stable) vertical temperature gradient through the box than in the experiments with a saline source (giving a similar density gradient), but there were no sharp interfaces.

We conclude that the critical factor causing the transition from full- to partial-depth convection in these experiments is the onset of a sufficiently large stabilizing buoyancy flux (whether provided by saline or cold water) from the source located at the heated end of the box. Also, for small ratios of 
the source to base buoyancy inputs, the flow behaviour does not depend on the molecular diffusivities of heat and salt. However, the details of the flow pattern generally do depend on whether double-diffusive processes are present. In the absence of double-diffusive convection, the oscillatory and intrusion regimes were not observed, nor were multiple layers or sharp interfaces. Finally, in the absence of salinity anomalies, the partial-depth convection returned to full-depth convection almost immediately after the source input was stopped, because removal of the cold source flow increased the net heat input and led to a stronger plume at the endwall.

\section{Discussion and conclusions}

The many simplifications employed to reduce the ocean overturning to a conceptual model amenable to laboratory study make it inappropriate to extrapolate our results to the oceans in a quantitative manner. However, analogies can be drawn, while keeping in mind the two-dimensional, nonrotating and purely buoyancy-forced nature of the laboratory model, and our use of the ideal (fixed temperature and fixed flux) thermal boundary conditions. The salt layer formed in the vicinity of the source in the experiments can be viewed as an analogue of the polar halocline produced by highlatitude freshwater input at the ocean surface. In the terms proposed by Stommel (1961), all of our regimes are 'thermally driven' modes. An analogue to the 'salinity-driven' mode would not be expected to occur in the present experiments, because there was no mechanism to increase the density of tropical surface waters to produce sinking in equatorial regions (i.e. as could be achieved by introducing freshwater in the vicinity of the cold plate). Hence, although regimes III and IV are strongly influenced by the salinity buoyancy input, the direction of circulation in each cell remains in the thermally driven sense. The 'quasi-steady' regime (I) found for small values of $B_{S} / B_{T}$ corresponds to a circulation with continuous bottom water formation. The self-sustained oscillations in the oscillatory regime (II) suggests a mechanism for cyclic growth and breakdown of the oceanic halocline, with corresponding fluctuations in bottom water formation rate. Although the dynamical controls on the oscillation period have not been identified, it was found that the period in the experiments varied from 0.7 to 1.4 times the convective ventilation timescale. If extrapolated to the oceans, this result would correspond to oscillation periods of around 1000-2000 years (taking the ocean ventilation timescale of approximately 1400 years as is found from $30 \mathrm{~Sv}$ of deep sinking filling an ocean of mass $1.4 \times 10^{21} \mathrm{~kg}$ with average density taken to be $1025 \mathrm{~kg} \mathrm{~m}^{-3}$; Gill, 1982). Cyclic fluctuations on timescales in this range are found in GCM simulations (e.g. Weaver et al., 1991) and in palaeoclimate records (where they include the Dansgaard-Oeschger cycles; Dansgaard et al., 1993). Thus, it seems plausible that the duration of such oscillations in the coupled atmosphereocean system could be determined primarily by the response of the oceans.

In the ocean context, the intrusion and flooding regimes (III and IV) would involve a reduction in the density of the 'surface' waters by freshwater input and a shutdown of the deep water production. A similar cessation of deep convection in the ocean is referred to as a 'polar halocline catastrophe' (Bryan, 1986) and these are thought to have occurred in past climates. Halocline catastrophes are also found in many forms of climate models (e.g. Weaver and Sarachik, 1991) involving atmosphere-ocean-ice sheet interactions in addition to the purely oceanic modes of response (to imposed changes in forcing) examined in the experiments. Once deep convection has shut down, the laboratory model exhibits strong hysteresis: the deep overturning circulation does not resume for a time much longer than the ventilation timescale (event (g) in Fig. 9). When the bottom thermal boundary conditions in the laboratory experiments were fixed, and after the salinity input had been turned off, the two-cell system evolved slowly by salt transport across the interface and eventually reached a fine balance in which the densities of the upper and lower cells were comparable. At this point the actual overturning event was rapid, signalling the transition from a partial-depth to a full-depth overturning.

The intrusion regime (III) corresponds to an oceanic situation in which a tongue of relatively cold, freshwater, stable at the surface in high latitudes, is subducted below the thermocline and spreads equatorwards to form a salinity minimum. This behaviour is reminiscent of Antarctic intermediate water, the low salinity signal of which can be traced as far north as $20^{\circ} \mathrm{N}$. The analogy extends to an enhancement of vertical mixing by salt fingering in the thermocline, and to stratification 
in surface polar regions of the ocean that is generally favourable to 'diffusive' interfaces and convecting layers.

The ratio of thermal and salinity buoyancy fluxes is the primary parameter determining the thermohaline behaviour. The present zonally integrated heat transport in the ocean in a single hemisphere is estimated to be approximately $1.5-2 \times 10^{15} \mathrm{~W}$ (Houghton et al., 1996; Macdonald, 1998). The net freshwater volume input (defined here as sum of the excess of precipitation over evaporation, plus river runoff and pack ice and icebergs leaving the ice sheets) into the high latitude oceans has been estimated as $0.45 \mathrm{~Sv}$ in the Northern Hemisphere and $0.27 \mathrm{~Sv}$ in the Southern Hemisphere, respectively (Open University Oceanography Course Team, 1989). The uncertainties in these freshwater inputs are substantial and estimated to be $0.2 \mathrm{~Sv}$ (Ganachaud and Wunsch, 2003). For the purpose of evaluating $B_{S}$, the source salinity density anomaly $\rho_{0} \beta \Delta S$ is given by the difference between the interior density $\rho_{0}=1025 \mathrm{~kg} \mathrm{~m}^{-3}$ and the density of freshwater $\rho \approx 1000 \mathrm{~kg} \mathrm{~m}^{-3}$ at $2{ }^{\circ} \mathrm{C}$. Thus, $B_{S} / B_{T}=$ 0.16-0.55 for the Northern Hemisphere, and $B_{S} / B_{T}=0.04-0.4$ for the Southern Hemisphere (where $c_{p}=3990 \mathrm{~J} \mathrm{~kg}^{-1}{ }^{\circ} \mathrm{C}^{-1}$ and $\alpha=7.81 \times$ $10^{-5}{ }^{\circ} \mathrm{C}^{-1}$, as appropriate for $T_{0}=2{ }^{\circ} \mathrm{C}$; Gill, 1982). These flux ratios are summarized in Table 1 and are comparable to the laboratory value for the transition to the 'flooding' regime in the experiments.

Note that the destabilizing salinity buoyancy flux owing to a net freshwater loss by evaporation at midlatitudes is modelled in the experiments only by the gradual increase of salinity in the interior of the tank relative to a fresher bottom boundary layer. Other ocean factors not included are geostrophic flow of the surface freshwater along meridional boundaries in the Arctic and North Atlantic, control of dense water production by sills between shallow seas and the open ocean, brine rejection from sea ice formation and cabbeling and thermobaric effects resulting from the nonlinear equation of state for seawater. Furthermore, we have modelled here only the response to a sudden onset of a freshwater influx with constant thermal boundary conditions. The results apply equally to the case of a sudden increase of an initially small freshwater buoyancy flux, but leave open questions about the response of the circulation to a more slowly increasing freshwater influx, simultaneous increase in the low-latitude evaporation rate and perturbed thermal boundary conditions (all of which are expected when transport in the hydrologic cycle is increased by a rise in global average temperature).

The critical values for the flux ratio can be understood in the context of the dynamics of 'horizontal convection'. In an equilibrium state there is no net heat or water input to the oceans and hence the stabilizing buoyancy imparted to the oceans at low latitudes by heating of surface waters to temperatures above that of the deep interior must be removed by high-latitude cooling. Similarly, the destabilizing buoyancy owing to evaporative water loss at low and mid latitudes is restored at an equal rate by freshwater input at high latitudes. Transport of the heat and salt requires a circulation which, if it is to be buoyancy-forced overturning, involves a small but essential 'overcooling' of some water (to $-2{ }^{\circ} \mathrm{C}$ in the Southern Hemisphere and to closer to $0{ }^{\circ} \mathrm{C}$ in the North Atlantic) below the interior abyssal temperature (approximately $1-3^{\circ} \mathrm{C}$ ). This overcooling is of the order of $3{ }^{\circ} \mathrm{C}$, or $10 \%$ of the $30^{\circ} \mathrm{C}$ overall temperature difference between tropical and polar water. This provides negative buoyancy sufficient to allow the present ocean sinking to large depths (Hughes and Griffiths, 2006; Hughes

Table 1

Summary of the heat throughput, high-latitude net freshwater input (or salt water input in the case of experiments) and range of buoyancy flux ratios

\begin{tabular}{llll}
\hline & Heat throughput $(\mathrm{W})$ & Input volume flux $\left(\mathrm{m}^{3} \mathrm{~s}^{-1}\right)$ & $B_{S} / B_{T}$ \\
\hline Experimental (i) & $67-255$ & $5.06 \times 10^{-13}-1.03 \times 10^{-9}$ & $0.02-0.064$ \\
Experimental (ii) & $70-258$ & $9.74 \times 10^{-13}-3.84 \times 10^{-9}$ & $0.057-0.32$ \\
Northern hemisphere & $(1.5-2) \times 10^{15}$ & $(0.25-0.65) \times 10^{6}$ & $0.16-0.55$ \\
Southern hemisphere & $(1.5-2) \times 10^{15}$ & $(0.07-0.47) \times 10^{6}$ & $0.04-0.40$ \\
\hline
\end{tabular}

The range of freshwater inputs to the high-latitude oceans are based on uncertainties of approximately $0.2 \mathrm{~Sv}$ (Ganachaud and Wunsch, 2003). The experimental results have been split into two cases - (i) continued deep water production (quasi-steady and oscillatory regimes) and (ii) cessation of deep overturning (intrusion and flooding regimes). 
et al., 2006). If the constant influx of freshwater is sufficiently small, it does not qualitatively alter the flow. However, the deep sinking can be shut down if the increase in the rate of freshwater buoyancy transport into the actively overturning part of the flow is greater than the fraction of the thermal buoyancy flux available there to force the sinking plume. These considerations alone suggest that the critical flux ratio (freshwater buoyancy input divided by the total thermal buoyancy loss associated with surface cooling) is small and of order 0.1 in both the ocean and the laboratory (see Hughes and Griffiths, 2006; Hughes et al., 2006). On the other hand, in the experiments much of the saline (analogous to freshwater) influx can be trapped in a stable surface layer and a shutdown of the deep overturning requires either: (1) in the case of a halocline of limited latitudinal extent, a sufficiently rapid mixing of freshwater downwards into the water column beneath the stable polar halocline (as in regime III identified in the experiments) so as to inhibit the sinking in the box-scale circulation or (2) spreading of the fresher stable surface layer to flood a large fraction of the cooled region of the ocean surface, causing the heat transport to be largely confined to a circulation trapped in the surface layer (as in regimes III and IV). The critical values of the input flux ratio $B_{S} / B_{T}$ are therefore determined by the ratio of mixing rates for salinity and thermal buoyancy across the halocline.

In the laboratory experiments, mixing through the halocline is dominated by 'diffusive' interfaces and convective layers, across which the ratio of buoyancy fluxes $r$ has been found to be $r \approx 0.15$ for local stability ratios $R_{\rho}>2$ (Turner, 1965) and rising to $r \sim 0.3$ as $R_{\rho}$ decreases to 1.2 (Taylor, 1988). Heat and salt input rates such that $B_{S} / B_{T}<r$ are required if there is to be a steady balance of salt in a small salt layer that covers less than the full area of the heated portion of the base of the laboratory tank. When $B_{S} / B_{T} \approx r$, the halocline must cover most of the heated portion of the base. The salinity buoyancy flux allowed by the double-diffusive interfaces, relative to the thermal buoyancy flux, is then sufficient to largely quash the deep overturning convection. When $B_{S} / B_{T}>r$, a balance cannot be achieved, the salinity buoyancy in the stable layer accumulates, and the halocline spreads across the whole of the base. Once this flooding has occurred, most of the meridional heat flux can be accommodated within the shallow layer (our discussion concerns only the transient flow in response to a change in freshwater input, and a two-layer stratification cannot persist indefinitely under constant surface forcing). When $B_{S} / B_{T}<r$, our experiments indicate that again a balance is not achieved, the flow in this case becoming oscillatory because salt is lost too rapidly from the halocline.

Although conditions in the ocean halocline are favourable to 'diffusive' interfaces and convecting layers, the larger importance of turbulent mixing (relative to the laboratory) implies that the ratio of fluxes carried by vertical mixing might be larger than 0.15 and the values of $B_{S} / B_{T}$ for which a steady salt balance is possible may be larger than that in the laboratory. However, the salinity buoyancy flux that will shut down the deep thermally forced sinking $(\sim 10 \%$ of the buoyancy flux owing to surface cooling) remains unchanged. The laboratory results are also roughly consistent with previous estimates from a simple conceptual model (Rahmstorf, 1996) and from an ocean-atmosphere coupled climate model (Rahmstorf, 1995; Ganopolski and Rahmstorf, 2001), both of which indicated that the critical perturbation (about the current state) to the freshwater inflow rate required for a switch in circulation modes is $\Delta Q \approx 0.24 \mathrm{~Sv}$ (for the North Atlantic heat transport of $10^{15} \mathrm{~W}$ ), or $\Delta\left(B_{S} / B_{T}\right) \approx 0.25$. This change in the buoyancy flux ratio represents the range of conditions over which hysteresis is observed, giving two possible stable circulation states. Our experiments have examined the flow behaviour with increasing freshwater influx and subsequent removal of this perturbation (which led to a slow return to the initial circulation). Thus, the critical flux ratio identified in the laboratory $\left(B_{S} / B_{T} \approx 0.15\right)$ is more properly compared with approximately one-half of the critical perturbation found in the climate model, or $\Delta\left(B_{S} / B_{T}\right) \approx 0.12$.

We conclude that the ratio of surface freshwater and thermal buoyancy fluxes is likely to play an important role in the oceans' thermohaline circulation. During adjustment of the ocean overturning to an increased freshwater input, buoyancy flux ratios greater than a critical value $B_{S} / B_{T} \sim 0.1$ are likely to cause significant fluctuations in the overturning. Larger values of this ratio may, at least temporarily, lead to a shutdown of the deep overturning and formation of a shallow upper ocean circulation largely isolated from the abyssal waters. The critical freshwater buoyancy input for shutdown of deep sinking is comparable to that portion of the buoyancy loss owing to surface cooling which is 
responsible for forcing the sinking plumes at depths beneath the thermocline.

\section{Acknowledgements}

We thank Tony Beasley and Chris Morgan for construction of the apparatus and assistance in the laboratory and Brad Ferguson for help with photography. Financial support was provided by the Australian Research Council (DP0664115).

\section{References}

Broecker, W.S., 1994. Massive iceberg discharges as triggers for global climate-change. Nature 372, 421-424.

Broecker, W.S., Peteet, D.M., Rind, D., 1985. Does the ocean-atmosphere system have more than one stable mode of operation? Nature 315, 21-26.

Broecker, W.S., Peng, T.-H., Jouzel, J., Russell, G., 1990. The magnitude of global fresh-water transports of importance to ocean circulation. Climate Dynamics 4, 73-79.

Bryan, F., 1986. High-latitude salinity effects and interhemispheric thermohaline circulations. Nature 323, 301-304.

Cenedese, C., Dalziel, S.B., 1998. Concentration and depth field determined by the light transmitted through a dyed solution. In: Carlomagno, Grant (Eds.), Eighth International Symposium on Flow Visualization, Sorrento, p. 61.

Colin De Verdiére, A.C., Jelloul, B.M., Sévellec, F., 2006. On the bifurcation structure of thermohaline millennial oscillations. Journal of Climate, in press.

Dansgaard, W., Johnsen, S.J., Clausen, H.B., Dahljensen, D., Gundestrup, N.S., Hammer, C.U., Hvidberg, C.S., Steffensen, J.P., Sveinbjornsdottir, A.E., Jouzel, J., Bond, G., 1993. Evidence for general instability of past climate from a $250-\mathrm{kyr}$ ice-core record. Nature 364, 218-220.

Ganachaud, A., Wunsch, C., 2003. Large-scale ocean heat and freshwater transports during the world ocean circulation experiment. Journal of Climate 16 (4), 696-705.

Ganopolski, A., Rahmstorf, S., 2001. Rapid changes of glacial climate simulated in a coupled climate model. Nature 409, $153-158$.

Gill, A.E., 1982. Atmosphere-Ocean Dynamics. International Geophysics Series, vol. 30. Academic Press, New York.

Houghton, J.T., Meira Filho, L.G., Callander, B.A., Harris, N., Kattenberg, A., Maskell, K., 1996. Climate Change 1995: the Science of Climate Change. Cambridge University Press, Cambridge.

Huck, T., Colin De Verdiére, A.C., Weaver, A.J., 1999. Interdecadal variability of the thermohaline circulation in box-ocean models forced by fixed surface fluxes. Journal of Physical Oceanography 29, 865-892.

Hughes, G.O., Griffiths, R.W., 2006. A simple convective model of the global overturning circulation, including effects of entrainment into sinking regions. Ocean Modelling 12, 46-79.

Hughes, G.O., Griffiths, R.W., Mullarney, J.C., Peterson, W., 2006. A theoretical model for horizontal convection at large Rayleigh number. Journal of Fluid Mechanics, in press.
Macdonald, A.M., 1998. The global ocean circulation: a hydrographic estimate and regional analysis. Progress in Oceanography 41, 281-382.

Manabe, S., Stouffer, R.J., 1995. Simulation of abrupt climate change induced by freshwater input to the North Atlantic Ocean. Nature 378, 165-167.

Marotzke, J., Willebrand, J., 1991. Multiple equilibria of the global thermohaline circulation. Journal of Physical Oceanography $21,1372-1385$.

Mullarney, J.C., 2004. Thermal and thermohaline convection models for the meridional overturning circulation of the oceans. Ph.D. Thesis, Australian National University.

Mullarney, J.C., Griffiths, R.W., Hughes, G.O., 2004. Convection driven by differential heating at a horizontal boundary. Journal of Fluid Mechanics 516, 181-209.

Open University Oceanography Course Team, 1989. Ocean Circulation, first ed. Pergamon Press, The Open University, Oxford.

Rahmstorf, S., 1995. Bifurcations of the Atlantic thermohaline circulation in response to changes in the hydrological cycle. Nature 378, 145-149.

Rahmstorf, S., 1996. On the freshwater forcing and transport of the Atlantic thermohaline circulation. Climate Dynamics 12, 799-811.

Rooth, C., 1982. Hydrology and ocean circulation. Progress in Oceanography 11, 131-149.

Rossby, H.T., 1965. On thermal convection driven by nonuniform heating from below: an experimental study. DeepSea Research 12, 9-16.

Rossby, T., 1998. Numerical experiments with a fluid heated nonuniformly from below. Tellus A 50A, 242-257.

Stocker, T.F., 2000. Past and future reorganizations in the climate system. Quaternary Science Reviews 19, 301-319.

Stocker, T.F., Wright, D.G., 1991. Rapid transitions of the oceans deep circulation induced by changes in surface-water fluxes. Nature 351, 729-732.

Stommel, H., 1961. Thermohaline convection with two stable regimes of flow. Tellus 13, 224-230.

Stommel, H., 1962. On the smallness of sinking regions in the ocean. Proceedings of the National Academy of Sciences, Washington 48, 766-772.

Taylor, J., 1988. The fluxes across a diffusive interface at low values of the density ratio. Deep-Sea Research 35, 555-567.

Te Raa, L.A., Dijkstra, H.A., 2002. Instability of the thermohaline ocean circulation on interdecadal timescales. Journal of Physical Oceanography 32, 138-160.

Turner, J.S., 1965. The coupled turbulent transports of salt and heat across a sharp density interface. International Journal of Heat and Mass Transfer 8, 759-767.

Tziperman, E., 1997. Inherently unstable climate behaviour due to weak thermohaline ocean circulation. Nature 386, 592-595.

Tziperman, E., 2000. Proximity of the present-day thermohaline circulation to an instability threshold. Journal of Physical Oceanography 30, 90-104.

Tziperman, E., Toggweiler, J.R., Feliks, Y., Bryan, K., 1994. Instability of the thermohaline circulation with respect to mixed boundary-conditions - is it really a problem for realistic models? Journal of Physical Oceanography 24, 217-232.

Walin, G., 1985. The thermohaline circulation and the control of ice ages. Palaeogeography, Palaeoclimatology, Palaeoecology 50, 323-332. 
Weaver, A.J., Sarachik, E.S., 1991. The role of mixed boundaryconditions in numerical-models of the oceans climate. Journal of Physical Oceanography 21, 1470-1493.

Weaver, A.J., Sarachik, E.S., Marotze, J., 1991. Fresh-water flux forcing of decadal and interdecadal oceanic variability. Nature 353, 836-838.

Weijer, W., Dijkstra, H.A., 2003. Multiple oscillatory modes of the global ocean circulation. Journal of Physical Oceanography 33, 2197-2213.

Whitehead, J.A., 1996. Multiple states in doubly driven flow. Physica D 97, 311-321.

Whitehead, J.A., Bradley, K., 2006. Laboratory studies of stratified convection with multiple states. Ocean Modelling 11.
Whitehead, J.A., Timmermans, M.L.E., Lawson, W.G., Bulgakov, S.N., Zatarain, A.M., Medina, J.F.A., Salzig, J., 2003. Laboratory studies of thermally and/or salinity driven flows with partial mixing-1. Stommel transitions and multiple flow states. Journal of Geophysical Research Oceans 108.

Whitehead, J.A., TeRaa, L., Tozuka, T., Keller, J., Bradley, K., 2005. Laboratory observations and simple models of slow oscillations in cooled salt-stratified bodies. Tellus A 57.

Winton, M., Sarachik, E.S., 1993. Thermohaline oscillations induced by strong steady salinity forcing of ocean generalcirculation models. Journal of Physical Oceanography 23, 1389-1410. 